\title{
Compreensão de professores acerca dos motivos da agressão de estudantes
}

\author{
Vladimir Sobkin, (D) I, Anna Fomitchenko, (D) II \\ ${ }^{I}$ Universidade de Moscou, Moscou, Rússia, RU \\ ${ }^{I I}$ Universidade Estatal de Orenburg, Rússia, $R U$
}

\begin{abstract}
Resumo
No presente artigo, analisam-se questões relacionadas aos motivos de manifestações de comportamentos agressivos dos estudantes dirigidos a professores, na Rússia. Tendo como ponto de partida notícias de fontes informativas sobre fatos reais de agressões no espaço escolar, o autor realizou uma investigação a respeito de como os professores compreendem os motivos que acreditam ser os mais significativos e que levam ao comportamento agressivo do aluno em relação ao professor. O artigo apresenta resultados de respostas a questionários aplicados a professores sobre os motivos que podem gerar comportamentos agressivos, destacando, especialmente, os mais significativos numa escala de 1 a 7 . Os resultados permitiram caracterizar a dinâmica etária da alteração do significado das diversas razóes para o comportamento agressivo de alunos dirigido ao professor para escolares dos anos iniciais, para escolares no limiar entre o primeiro e o segundo segmentos do ensino fundamental, para os que se encontram na etapa de transição para a adolescência, os da etapa final do segundo segmento do ensino fundamental ( $9^{\circ}$ ano) e os da etapa final da escola $\left(11^{\circ}\right.$ ano). Palavras-chave: agressão; motivos; professor; estudante.
\end{abstract}

\section{Teachers' understanding of motives for students aggression}

\section{Abstract}

In the present article it is analyzed issues related to the motives for manifestations of aggressive behavior of students towards teachers, in Russia. We took as starting point for this analysis some news from informative sources about real facts of aggression in the school space. Then, it was conducted an investigation which aimed to identify how teachers understand the most significant reasons pointed by them why students present aggressive behavior towards teachers. The article presents results of answers to questionnaires applied to teachers about the motives that can generate aggressive behaviors, especially highlighting the most significant ones on a scale from 1 to 7. The results allowed us to characterize the age dynamics of the change in the meaning of the various reasons for the aggressive behavior of students directed to the teacher for students in the early years, for students in the threshold between the first and second segment of elementary school, and for those in the transition phase to adolescence

Keywords: aggression; motives; teacher; student.

\author{
Um conflito entre o professor e a criança \\ é uma grande tragédia para a escola. \\ Frequentemente, o conflito surge \\ quando o professor tem uma percepção \\ injusta da criança.
}

(SURHOMLINSKI, 1981, p. 192).

$\mathrm{O}$ intenso crescimento de diferentes tipos e formas de comportamento agressivo em crianças e adolescentes tem provocado grande preocupação entre estudiosos russos e estrangeiros (BANDURA; UOLTERS, 2000; BRESLAV, 2007; BERON; RITCHARDSON, 2001; BUTNER, 1991; ENIKOLOPOV, 2002; KOLOSSOVA, 2000; KREIRHI, 2003; REAN, 2007; SOBKIN et al., 2005; ERIKSON, 2006). Há, contudo, interesse especial nas manifestações de agressão de crianças e adolescentes entre os muros de instituições escolares.

De fato, por um lado, a escola é uma das instituições mais importantes de socialização, que, por seu caráter educacional, tem como objetivo a assimilação pelos estudantes de exemplos positivos de comportamento. Ela deve ensinar às crianças a cultura das relações com seus coetâneos e adultos, tanto durante as atividades escolares como além delas. Existem documentos normativos que regulamentam regras de organização do processo

\footnotetext{
^Endereço para correspondência: Universidade de Moscou, Faculdade de Psicologia, Ulitsa Mokhovaia, 11/st. 9, Moscou, Rússia. E-mails: sobkin@mail. ru,anzitadel@mail.ru

Os dados completos dos autores encontram-se ao final do artigo.
}

de estudo escolar e normas de relação social no âmbito da instituição de ensino. Ao mesmo tempo, diferentes tipos de manifestações agressivas de adultos e crianças transformam-se em tabu. Vale acrescentar que normas da ética profissional pedagógica excluem manifestações de agressão aos estudantes. Por outro lado, apesar de proibições e sanções em relação às manifestações agressivas nas escolas, a quantidade de situações conflituosas cresce vertiginosamente $^{1}$ (SOBKIN, 2003).

Atualmente, discutem-se ativamente, nos meios de informação, questões relativas a manifestações de crueldade por parte do professor. Pelos dados de News.ru (ЭСКАЛАЦИЯ..., 2007), nos últimos anos, o número de processos criminais abertos contra professores acusados de maus-tratos a estudantes aumentou muito. Periodicamente, na imprensa, são analisados os casos mais gritantes. Eis alguns exemplos:

Terminou em tragédia a conversa difícil no gabinete do diretor de uma escola de Moscou. O aluno do $9^{\circ}$ ano foi acusado de ter levado uma garrafa de vinho para a excursão $e$, por isso, foi solicitado, categoricamente, que ele se retirasse da escola. O rapaz se suicidou. Alguns dias depois, a diretora da escola faleceu, vítima de infarto.

Na região de Sverdlov, durante atividades de limpeza do estádio escolar, o professor de educação fisica bateu com o

${ }^{1}$ ESCALADA da violência nas escolas: em dois anos, a quantidade de ataques a professores aumentou muito (ЭСКАЛАЦИЯ..., 2007).

Recebido em: 1 de junho de 2019

$1^{\text {a }}$ avaliação: 7 de julho de 2019 $2^{\mathrm{a}}$ avaliação: 10 de agosto de 2019 Aceito em: 28 de novembro de 2019 
ancinho em dois estudantes do $9^{\circ}$ ano, provocando feridas de perfuração. O professor foi multado em 5.000 rublos $e$ demitido pelo diretor.

Em Tiumen, uma professora de lingua inglesa de 58 anos rasgou a orelha de uma moça de 16 anos por tê-la puxado com muita força. O processo criminal foi aberto de acordo com o artigo $156^{\circ}$ do Código Penal da Federação Russa pelo 'não cumprimento de suas obrigações na educação de menores de idade'. A professora foi demitida e está aguardando a sentença.

Parece que, em Primorie, uma professora obrigou sete estudantes do $4^{\circ}$ ano a lamberem, na presença de outros colegas, as marcas de sapatos deixadas no chão após uma brincadeira. Foi feito um boletim de ocorrência.

Na Repúbica Sarra (Iakutia), “com intenções pedagógicas", o professor de trabalhos manuais bateu na cabeça de aluno do $6^{\circ}$ ano com uma chapa de fibra de madeira, causando à criança uma ferida aberta na nuca. O juiz condenou o professor a pagar uma multa de 5.000 rublos "por ter causado feridas, que não acarretaram danos temporários à saúde", segundo o artigo $116^{\circ}$ do Código Penal da Federação Russa.

Em São Petersburgo, a professora batia com a régua nas mãos dos alunos e com o apoio de livros na cabeça deles, caso conversassem durante as aulas, além de obrigá-los a darem cabeçadas uns nos outros. O aluno que recusasse o almoço era obrigado a comer a sopa misturada com o segundo prato. Foi aberto um processo penal.

Mais um caso escandaloso. O corpo de Roman Lebedev, de 14 anos, foi encontrado sob a plataforma da ferrovia da estação Skatchki. No bolso do casaco do menino foi encontrado um bilhete em que ele acusava o professor supervisor da turma pelo ocorrido. Foi apresentada ao professor a acusação, de acordo com três artigos do Código Penal da Federação Russa: $110^{\circ}$ ("levar ao suicídio"), $130^{\circ}$ ("humilhação") e $156^{\circ}$ ("não cumprimento de suas obrigações na educação de menores de idade").

Exemplos como esses se multiplicam indefinidamente. Porém, são numerosos e impressionantes, também, por sua crueldade, os casos em que o objeto de agressão é o professor. Apresentamos exemplos de comportamento agressivo de estudantes em relação ao professor, ativamente discutidos na imprensa.

Em Krasnoiarsk, a aluna do $8^{\circ}$ ano aguardou, após as aulas, a professora e desferiu-lhe uma série de facadas. Testemunhas chamaram a ambulância. Algumas horas depois, a menina foi presa em sua casa enquanto fazia as tarefas escolares. Quando a polícia chegou, Marina perguntou tranquilamente: "O quê? Ela não morreu?".

Um aluno do $5^{\circ}$ ano de uma escola moscovita que não fez a lição de casa bateu na professora de 55 anos. O motivo do ataque foi a pergunta: "Seus pais, ao menos, se interessam pelo seu aproveitamento?" O menino, que desferiu um soco no rosto e outro na barriga da mulher, explicou suas ações da seguinte forma: "Por que ela fica brigando comigo? E além do mais, fica humilhando meus pais, como se eles não se preocupassem comigo [...]"
Em Kuban, três alunos do ensino médio invadiram a casa de uma professora idosa de educação fisica, estupraram-na e, em seguida, mataram-na cruelmente. Pela manhã, compareceram à aula de educação física e ficaram indignados com o fato de a aula ter sido suspensa por causa da professora. Os criminosos já tinham 14 anos, por isso, foram condenados a muitos anos de internação.

Apresentou-se a um aluno do $11^{\circ}$ ano de Irkutsk a acusação de ter desferido 9 facadas no professor de física por não ter sido aprovado na matéria.

Tais casos não são isolados, ocorrem também no estrangeiro.

Em Berlim, o libanês de 15 anos, em resposta à exigência de manter silêncio durante a aula, bateu com sua testa no rosto do professor de matemática, quebrando-lhe o nariz e machucando os lábios do senhor de 61 anos; o diretor da escola do bairro Neukeln foi cruelmente atacado por seus alunos; um adolescente de 12 anos de Kreuzberg quase deixou a professora cega de um olho ao desferir-lhe um soco; na região do zoológico de Berlim, uma aluna do ensino médio aguardava sua professora de língua inglesa com um revólver em sua mochila, pois não queria mais "receber notas baixas", etc.

Como é possível observar, as manifestações de agressão de alunos ao professor tornaram-se realidade do cotidiano. Para confirmar isso, vamos nos remeter a dados obtidos por meio de questionários aplicados a 104 professoras de escolas comuns. Foi-lhes apresentada a opção de escolher e descrever situações de manifestação de agressão de alunos ao professor as quais elas testemunharam ou das quais participaram. A pesquisa foi realizada em 2008 e 2009 pelo Instituto de Sociologia da Educação da Academia Russa de Educação (ARE) (SOBKIN; FOMITCHENKO, 2011). A análise dos questionários, com foco na descrição de diferentes formas de agressão dos estudantes ao professor, evidenciou um percentual elevado do emprego de agressão verbal (46\%) e de agressão indireta $(43 \%)$. Foram consideradas como agressão verbal ofensas verbais, palavrões e gritos. Eis alguns extratos dos textos das professoras:

Depois de uma exigência insistente da professora, o aluno entregou de forma brusca o seu diário. Falou em voz alta, com raiva, de forma grosseira e com ódio: "Vocês não sabem ensinar patavina; todos vocês, professores, sabem apenas ameaçar".

Uma situação de conflito ocorreu na aula quando, em resposta ao pedido do professor de preparar os pertences escolares e iniciar a tarefa, um aluno do $6^{\circ}$ ano começou a dirigir palavras desrespeitosas ao professor, manifestando agressão verbal; o menino fazia papel de um palhaço em sala de aula.

Na realização de uma prova, o estudante I. exigiu insistentemente que seu colega $K$. lhe desse as respostas às perguntas. Por isso, o professor atribuiu nota "zero" ao aluno $K$. Indignado com a situação criada, histericamente, esse aluno proferiu as seguintes palavras: "Deixem-me em paz, vão todos para...”, pronunciando palavrões. 
Finalmente, o professor se cansou da turma que ignorava sua matéria e nomeou como líderes informais os alunos que mais o importunavam, o que deu inicio a xingamentos constantes que destacavam seus pontos fracos diante da turma inteira. Certa vez, um silêncio se instalou na sala de aula enquanto o professor escrevia no quadro. De repente, acima da sua cabeça, arrebentou-se um vaso de planta, derramando terra no seu terno.

São bastante ilustrativos também os resultados de manifestações de agressões indiretas. Esse dado mostra que o professor diferencia as diversas formas de manifestações. "Saiu da sala de aula, batendo a porta com força"; "Jogou no chão os livros que estavam em cima da carteira, jogou a mochila - essas eram as reações à reprimenda do professor"; "L. saltou e socou a parede".

Vale destacar que o problema das relações entre professor e estudantes não surgiu hoje e já foi objeto de atenção de muitos pedagogos-cientistas: de A. S. Makarenko, de V. A. Surhomlinski, de Ch. A. Amonachvili, de O. S. Gazman, entre outros. Por exemplo, em sua obra Poema pedagógico, A. S. Makarenko (1981), mais de uma vez, mostrou a agressão de educandos a si próprios e a professores.

Vale destacar, também, que a agressão de estudantes ao professor é um fenômeno extremamente perigoso. Há deformação das normas de relação social e de papéis professor-aluno: o professor como um adulto social deixa de coordenar o processo de instrução, perdendo sua autoridade profissional e pessoal. Por isso, a transgressão às normas de relação social e dos papéis professor-aluno exige uma análise psicológica especial.

Ao falar da transgressão às normas de relação social e dos papéis professor- aluno, é importante chamar a atenção para o fato de que há interesse especial no estudo das particularidades da compreensão dos professores acerca dos motivos do surgimento do comportamento agressivo de estudantes dirigido ao professor, ou seja, como é percebida a situação de agressividade infantil do ponto de vista do objeto da agressão - o professor? Assim, é importante evidenciar a peculiaridade da compreensão do professor acerca dos principais motivos que circunscrevem a agressividade dos estudantes de diferentes idades, compreender a dinâmica de alteração da compreensão do professor acerca dos motivos da agressividade infantil, considerando a idade e o gênero dos estudantes.

A análise de trabalhos da psicologia das idades permite demarcar possíveis dominantes motivacionais que determinam o comportamento agressivo de estudantes de diversos grupos etários em relação aos professores.

Assim, por exemplo, para a criança do primeiro segmento do ensino fundamental $(\mathrm{EF})$, o professor é uma figura central que define para o aluno as regras no novo sistema de relações, no âmbito do qual se desdobra a atividade de estudo escolar. Tendo isso em conta, é possível supor que a manifestação de agressão do aluno ao adulto socialmente significante para ele, nessa faixa etária, seja um tabu.

Adolescentes do final do primeiro segmento do EF ( $5^{\circ}$ ano), em comparação com estudantes dos anos iniciais, são mais sensíveis em relação a problemas pessoais que surgem nas atividades escolares e em relação às capacidades necessárias para a realização bem-sucedida dos estudos. Por isso, pode-se supor que, nesse grupo etário, a agressão dos estudantes ao professor seja provocada, em maior grau, via ações do professor que humilha os alunos.

No segundo segmento do EF ( $7^{\circ}$ ano), os alunos começam a ter uma relação diferenciada com os professores, o que, por sua vez, depende das especificidades da relação que o professor mantém com eles. Por isso, é possível supor que um dos motivos de manifestações de agressões dos alunos ao professor sejam fatores ligados à avaliação não-objetiva dos seus conhecimentos. Além disso, nessa idade, formam-se nos escolares traços estáveis de caráter e modos de reação emocional. Isso permite evidenciar peculiaridades dos alunos que os professores registram como razão para um comportamento agressivo.

A adolescência se diferencia pela sua situação peculiar na transição para a vida adulta. A relação de convivência com professores se forma sob forte influência do sentimento de se tornar adulto. Os adolescentes defendem ativamente seus direitos e pontos de vista, e a formação de critérios de avaliação da atividade e da personalidade do adulto permite-lhes definirem a qualidade do ensino do professor. Além disso, nesse período crítico, os estudantes são muito sensíveis a ataques reais ou aparentes em relação a sua pessoa. Finalmente, a relação de convivência dos adolescentes com seus coetâneos (identificação com um grupo) tem um significado ímpar. Assim, pode-se supor que os motivos de manifestação de comportamento agressivo dirigido ao professor, nos adolescentes mais velhos, podem estar relacionados às divergências ideológicas com o professor, às humilhações que este faz a cada um ou à turma inteira, como também à transgressão das normas na atividade escolar cometida pelo professor.

\section{Metodologia}

Para o estudo das particularidades da compreensão dos professores acerca dos motivos da manifestação de agressão de estudantes, empregamos uma metodologia especial, utilizando o princípio de atribuição motivacional (GRATCHIOVA et al., 1988; SOBKIN; MARKINA, 2009, 2010). Ela consiste na avaliação da probabilidade de determinadas razões serem motivos que circunscrevem o comportamento agressivo de alunos em relação ao professor.

Com esse objetivo, propunha-se a professores de escolas comuns avaliarem, numa escala de 7 , em que 1 significa totalmente insignificante e 7 , muito significante, o grau de importância de diversos motivos que circunscrevem o comportamento agressivo de alunos dirigido ao professor. Para a avaliação, oferecia-se aos participantes do estudo uma lista com 42 razões selecionadas com base na análise de trabalhos dedicados à agressividade infantil. Convencionalmente, elas podem ser relativas a cinco grupos: 1) características individuais do aluno (instabilidade emocional, atipia física e psicológica, falta de educação/grosseria, etc.); 2) divergências ideológicas (choque de interesses, de valores, de opiniões, defesa dos próprios pontos de vista, entre outros); 3) diversos momentos em que a agressão do aluno é provocada di- 
retamente pelo professor (antipatia pessoal, humilhação do aluno, humilhação dos responsáveis pelo aluno, etc.); 4) razões relacionadas a aspectos sociais da atividade escolar (divergência em um determinado tema, elevado nível de exigências por parte do professor em relação ao aproveitamento escolar e ao comportamento do aluno, autoritarismo do professor, baixo profissionalismo do professor, entre outras); 5) fatores sociais (baixo nível socioeconômico da família, atmosfera de desavenças na família, rigidez da família no trato com a criança, etc.).

Durante a aplicação do questionário, os professores avaliaram a probabilidade das 42 razões propostas que circunscreveriam atos agressivos dirigidos ao professor por meninos e meninas de diferentes grupos etários $\left(2^{\circ}, 5^{\circ}, 7^{\circ}, 9^{\circ}\right.$ e $11^{\circ}$ anos escolares). Esse procedimento metodológico permite obter um material que mostra a compreensão dos professores acerca do significado das razões ligadas às manifestações de agressão por parte de estudantes de diferentes idades e as compara com as especificidades motivacionais do comportamento agressivo de meninos e meninas.

Responderam ao questionário 200 professores de escolas comuns. Aqui, são analisadas as avaliações médias obtidas para cada motivo.

Antecipando a análise dos resultados, é importante destacar que, partindo do conteúdo da avaliação na escala de 7 (em que 1 é totalmente insignificante, 2 é insignificante, 3 é praticamente insignificante, 4 é indefinidamente significante, 5 é pouco significante, 6 é significante e 7 é muito significante), o significado real das razões para a agressão de estudantes ao professor evidencia-se com a nota 3,5. Assim, razões avaliadas pelos professores com nota abaixo de 3,5 foram excluídas da análise.

\section{Características individuais dos estudantes}

Entre as razões que fazem parte do presente bloco de conteúdos, três mostraram-se significantes: instabilidade emocional, baixo nível de autocontrole, falta de educação/grosseria. A avaliação pelos professores das razões significantes para o comportamento agressivo de meninos e meninas de diferentes grupos etários é apresentada nas Figuras 1 e 2.

Figura 1 - Avaliação pelos professores das características individuais dos meninos que são motivos para a agressão ao professor por ano escolar.

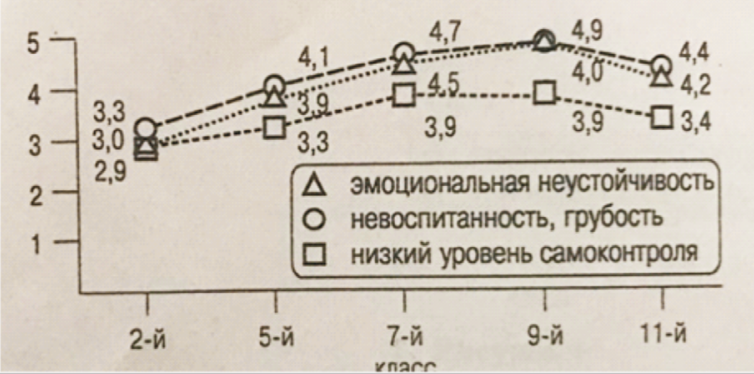

Legendas:

$\triangle$ Instabilidade emocional (............)

Falta de educação/grosseria (....

$\square$ Baixo autocontrole (- . - . )
Figura 2 - Avaliação pelos professores das características individuais das meninas que são motivos para a agressão ao professor por ano escolar

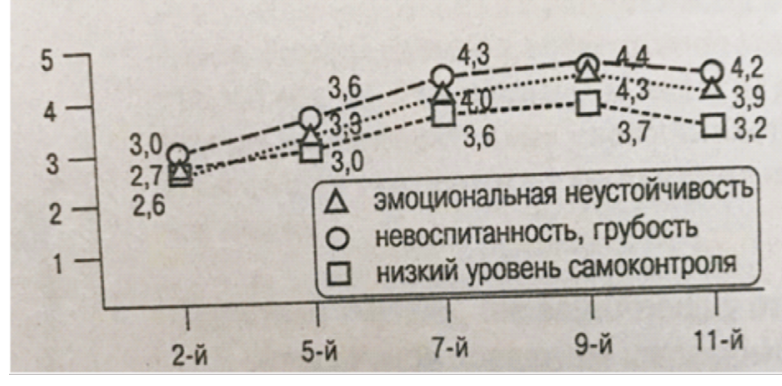

Legendas:

$\triangle$ Instabilidade emocional (............)

$\bigcirc$ Falta de educação/grosseria (_... _ _ $)$

$\square$ Baixo autocontrole (- - - - - )

Como é possível perceber, em geral, a dinâmica das alterações em meninos e meninas é semelhante: do $2^{\circ}$ ao $9^{\circ}$ ano eleva-se gradualmente o significado da instabilidade emocional, da falta de educação/grosseria, do baixo nível de autocontrole como razões que circunscrevem o comportamento agressivo de escolares dirigido ao professor. Na etapa etária seguinte (do $9^{\circ}$ ao $11^{\circ}$ ano), a elevação do significado das razões desacelera-se.

Também chama a atenção o fato de que as razões para o comportamento agressivo de alunos do $2^{\circ}$ ano são insignificantes, pois receberam notas abaixo de 3,5. Quando são mais velhos (no $5^{\circ}$ ano), a instabilidade emocional e a falta de educação/grosseria começam a figurar na zona de razões significantes. À medida que a idade avança $\left(7^{\circ}\right.$ e $9^{\circ}$ anos), as três razões obtêm notas máximas. Dessa forma, no limiar dessa idade, são essas razões, segundo os professores, que circunscrevem as manifestações de agressão dos alunos aos professores. Nas últimas etapas escolares (do $9^{\circ}$ ao $11^{\circ}$ ano), os indicadores de todas as características reduzem-se, e os mais significantes são a instabilidade emocional e a falta de educação/grosseria.

Assim, os dados apresentados permitem descrever uma dinâmica bastante complexa de alteração do significado das características individuais dos alunos (a instabilidade emocional, grosseria e baixo autocontrole) como fatores que circunscrevem a manifestação de agressões ao professor. Entretanto, podemos destacar que, no início da trajetória escolar, as singularidades do aluno nem sequer são analisadas pelos professores como razões significantes para manifestação de agressão da criança ao professor. Porém, à medida que os alunos ficam mais velhos (no segundo segmento do ensino fundamental), as características individuais começam a ser registradas pelos professores como fatores significantes que determinam as manifestações agressivas no âmbito da matriz das relações sociais e de papéis professor-aluno. Assim, na etapa final do segundo segmento do ensino fundamental ( $9^{\circ}$ ano), características individuais são avaliadas como dominantes motivacionais significantes que circunscrevem as manifestações de agressão do aluno ao professor. 


\section{Divergências ideológicas}

Para os alunos dos primeiros anos da escola e os que estão no final do segundo segmento do EF, as razões atribuídas a esse grupo não foram avaliadas pelos professores como fatores significantes que circunscrevem o comportamento agressivo de escolares dirigido ao professor. Apenas na etapa final do ensino fundamental e numa idade maior, essas razões tornam-se significantes. Além disso, as divergências de conteúdo ideológico não são analisadas pelos professores como fatores que propiciam a manifestação de agressão dirigida a si. Nesse momento, apenas aspectos comportamentais que registram peculiaridades da relação mostram-se significantes - defesa do seu ponto de vista. Em geral, o significado das divergências ideológicas como fator que determina o comportamento agressivo de alunos em relação ao professor eleva-se de acordo com a idade. A tendência é geral entre meninos e meninas.

\section{Ações do professor que provocam comportamento agressivo de escolares}

A análise do material obtido mostra que o professor assinala um espectro amplo de diferentes ações que podem provocar comportamento agressivo nos alunos (Tabela 1). Esse fato permite a seguinte conclusão: os professores são críticos em relação ao seu próprio comportamento e ao comportamento de seus colegas quando lidam com os alunos.

Os dados apresentados na Tabela 1 requerem algumas explicações. Podemos ver que, em relação aos alunos dos anos iniciais da escola ( $2^{\circ}$ ano), os professores praticamente não assinalam qualquer ação própria que possa provocar um ato agressivo da criança. Assim, a matriz da relação social e dos papéis professor-aluno é percebi- da por eles conforme a lógica da hierarquia vertical das relações sociais, o que exclui a agressão da criança. Parece-nos que o único momento que circunscreve a possibilidade de reações agressivas do aluno é aquele em que o professor o ameaça de comunicar aos responsáveis seu mau comportamento ou rendimento escolar. Vale ressaltar que, no segundo segmento do EF, o significado dessa razão também é bem alto.

Chama a atenção o grande conjunto de padrões comportamentais de caráter agressivo em relação ao aluno que circunscreve a resposta como reação defensiva no segundo segmento do EF: a antipatia do professor em relação ao aluno, humilhação, atribuição de estereótipos, emprego de força física. É importante dizer que o significado desses fatores, ligados à humilhação do escolar, aumenta consideravelmente quando são avaliadas as manifestações de agressão dos alunos do $9^{\circ}$ ano. O aumento do significado desses fatores evidencia não apenas o fato de que os professores manifestam uma agressividade maior em relação ao adolescente, como também que, nessa etapa, o escolar mostra-se mais sensível às reações negativas manifestadas em relação a ele pelo professor. Assim, por meio do professor, podemos assinalar a peculiaridade da manifestação da crise de identidade na etapa de transição do adolescente para o jovem (ERIKSON, 2006).

Nessa idade, atualizam-se problemas relacionados à autoidentificação, à autodeterminação, à busca de respostas à questão: como sou aos olhos de outras pessoas? (BOJOVITCH, 1968; ERIKSON, 2006). E mais, é muito comum que essa percepção na avaliação negativa da própria personalidade por parte do professor esteja correlacionada com o aumento de reações de defesa, de autodefesa e vingança por parte do humilhado (ver Tabela 1).

Tabela 1 - Como professores avaliam as ações do professor que são motivos para resposta agressiva de estudantes (notas).

\begin{tabular}{|c|c|c|c|c|c|c|c|c|c|c|}
\hline \multirow{2}{*}{$\begin{array}{l}\text { Razões para } \\
\text { manifestações de } \\
\text { agressão do aluno ao } \\
\text { professor }\end{array}$} & \multicolumn{2}{|c|}{$\begin{array}{l}2^{\circ} \text { ano } \\
92 \text { pessoas }\end{array}$} & \multicolumn{2}{|c|}{$\begin{array}{l}5^{\circ} \text { ano } \\
107 \text { pessoas }\end{array}$} & \multicolumn{2}{|c|}{$\begin{array}{l}7^{\circ} \text { ano } \\
116 \text { pessoas }\end{array}$} & \multicolumn{2}{|c|}{$\begin{array}{l}9^{\circ} \text { ano } \\
109 \text { pessoas }\end{array}$} & \multicolumn{2}{|c|}{$\begin{array}{l}11^{\circ} \text { ano } \\
103 \text { pessoas }\end{array}$} \\
\hline & $\mathrm{m}$. & f. & $\mathrm{m}$. & f. & $\mathrm{m}$. & f. & $\mathrm{m}$. & f. & $\mathrm{m}$. & f. \\
\hline $\begin{array}{l}\text { Antipatia do professor em } \\
\text { relação ao aluno }\end{array}$ & 2,7 & 2,7 & 3,5 & 3,4 & 4,1 & 4,0 & 4,9 & 4,9 & 4,7 & 4,7 \\
\hline Humilhação do aluno & 2,9 & 2,9 & 3,8 & 3,9 & 4,7 & 4,6 & 5,4 & 5,5 & 5,4 & 5,4 \\
\hline $\begin{array}{l}\text { Atribuição de estereótipos } \\
\text { ao aluno }\end{array}$ & 2,2 & 2,2 & 3,1 & 3,1 & 3,8 & 3,8 & 4,6 & 4,7 & 4,4 & 4,4 \\
\hline $\begin{array}{l}\text { Emprego de força física } \\
\text { com o aluno }\end{array}$ & 3,4 & 3,5 & 4,0 & 4,0 & 4,5 & 4,3 & 5,2 & 5,1 & 4,9 & 4,9 \\
\hline $\begin{array}{l}\text { Ameaça de comunicar o } \\
\text { mau comportamento ou } \\
\text { rendimento } \\
\text { responsáveis }\end{array}$ & 4,1 & 3,9 & 4,6 & 4,5 & 4,8 & 4,5 & 4,8 & 4,6 & 4,1 & 3,9 \\
\hline $\begin{array}{l}\text { Humilhação dos } \\
\text { responsáveis pelo aluno }\end{array}$ & 3,1 & 3,1 & 4,1 & 4,1 & 4,8 & 4,7 & 5,5 & 5,6 & 5,5 & 5,4 \\
\hline $\begin{array}{l}\text { Relação desrespeitosa do } \\
\text { professor com a turma }\end{array}$ & 2,3 & 2,3 & 3,3 & 3,3 & 4,0 & 4,1 & 4,9 & 4,9 & 4,8 & 4,7 \\
\hline $\begin{array}{lrrr}\begin{array}{l}\text { Solução } \\
\text { conflito } \\
\text { professor }\end{array} & \begin{array}{r}\text { injusta } \\
\text { dada }\end{array} & & \text { pelo } \\
\text { pelo }\end{array}$ & 3,0 & 2,9 & 4,1 & 4,1 & 4,4 & 4,4 & 5,1 & 5,1 & 5,0 & 5,1 \\
\hline Autodefesa & 2,9 & 2,4 & 3,6 & 3,3 & 4,1 & 3,9 & 4,6 & 4,3 & 4,4 & 4,0 \\
\hline Vingança & 2,8 & 2,5 & 3,4 & 3,3 & 3,8 & 3,6 & 4,3 & 3,9 & 4,2 & 3,8 \\
\hline
\end{tabular}

Legenda: $\mathrm{m}$ - masculino; $\mathrm{f}-$ feminino. 
É importante chamar a atenção para dois aspectos. Um deles relaciona-se à avaliação negativa dos responsáveis feita pelo professor. A sensibilidade do adolescente a essas avaliações é motivo de agressão ao professor já no $5^{\circ}$ ano e aumenta à medida que o aluno fica mais velho. $\mathrm{O}$ outro aspecto guarda relação com a avaliação negativa da turma inteira feita pelo professor (solução injusta de um conflito). O significado disso manifesta-se claramente na avaliação dos motivos para o comportamento agressivo dos alunos do $7^{\circ}$ ano.

Em geral, os dados apresentados mostram que o comportamento agressivo do aluno em relação ao professor circunscreve-se à atualização dos mecanismos de identificação do adolescente com adultos que são importantes para ele (seus responsáveis) e com seus coetâneos. Além disso, no último caso, a autoidentificação com um grupo tem grande importância. Assim, manifesta-se uma linha peculiar que circunscreve o comportamento agressivo do adolescente em relação ao professor, linha que se liga a mecanismos de defesa, quando o motivo é a agressão do professor a pessoas importantes do círculo próximo do adolescente. Ao mesmo tempo, isso comprova também a sensibilidade deste em relação às pessoas próximas.

\section{Razões relacionadas a aspectos sociais da atividade de estudo}

Na Tabela 2, apresenta-se um conjunto de razões que circunscrevem a agressão de escolares ao professor e se relacionam diretamente com a atividade escolar.
Pela Tabela 2 é possível observar que, no $2^{\circ}$ e no $5^{\circ}$ ano, os professores não assinalam aspectos relacionados à atividade de estudo como significativos para manifestação de agressão de alunos ao professor. Ou seja, as relações sociais e de papéis professor- aluno, ligadas diretamente à atividade de estudo, formam um tabu na manifestação de agressão de alunos ao professor, nessa etapa inicial da escola e no final do segundo segmento do EF. Apenas no $7^{\circ}$ ano surgem situações de conflito que podem levar à agressão do aluno ao professor. $\mathrm{O}$ fator-chave é a avaliação não objetiva dos conhecimentos pelo professor. Destaca-se que é essa a razão predominante também nas outras faixas etárias (no $9^{\circ}$ e no $11^{\circ}$ ano). Além disso, em adolescentes mais velhos (no $9^{\circ} \mathrm{e}$ no $11^{\circ}$ ano), um fator significativo para manifestação de agressão é o nível elevado de exigência do professor em relação ao rendimento/comportamento do aluno.

A influência das relações sociais e de status (competição pela liderança, tendência a demonstrar superioridade no grupo) manifesta-se de modo peculiar. Segundo os professores, elas são mais significativas nos alunos do $9^{\circ}$ ano. Provavelmente, isso guarda relação com a crise da idade vivenciada nessa época, com o sentimento de adentrar-se na idade adulta. Nesse limiar etário, o adolescente tende a alterar a hierarquia verticalizada das relações sociais e de papéis professor-aluno. Ligam-se a isso, também, as avaliações negativas da posição do próprio professor, seu autoritarismo e baixo nível de profissionalismo.

Tabela 2 - Avaliação dos professores dos fatores sociais que se apresentam como razões para agressão de meninos e meninas ao professor (notas)

\begin{tabular}{|c|c|c|c|c|c|c|c|c|c|c|}
\hline \multirow{2}{*}{$\begin{array}{l}\text { Razões para } \\
\text { manifestações de agressão } \\
\text { do aluno ao professor }\end{array}$} & \multicolumn{2}{|c|}{$\begin{array}{l}2^{\circ} \text { ano } \\
92 \text { pessoas }\end{array}$} & \multicolumn{2}{|c|}{$\begin{array}{l}5^{\circ} \text { ano } \\
107 \text { pessoas }\end{array}$} & \multicolumn{2}{|c|}{$\begin{array}{l}7^{\circ} \text { ano } \\
116 \text { pessoas }\end{array}$} & \multicolumn{2}{|c|}{$\begin{array}{l}9^{\circ} \text { ano } \\
109 \text { pessoas }\end{array}$} & \multicolumn{2}{|c|}{$\begin{array}{l}1^{\circ} \text { ano } \\
103 \text { pessoas }\end{array}$} \\
\hline & $\mathrm{m}$. & f. & $\mathrm{m}$. & f. & $\mathrm{m}$. & f. & $\mathrm{m}$. & f. & $\mathrm{m}$. & f. \\
\hline Autoritarismo do professor & 2,0 & 2,0 & 2,5 & 2,5 & 3,3 & 3,3 & 4,1 & 4,1 & 3,9 & 3,7 \\
\hline $\begin{array}{l}\text { Baixo nível profissional do } \\
\text { professor }\end{array}$ & 1,9 & 1,8 & 2,6 & 2,5 & 3,1 & 3,1 & 3,9 & 4,0 & 4,1 & 4,1 \\
\hline Competição por liderança & 2,6 & 2,4 & 3,2 & 3,1 & 3,8 & 3,8 & 4,5 & 4,1 & 4,1 & 3,8 \\
\hline $\begin{array}{l}\text { Tendência a mostrar } \\
\text { superioridade no grupo }\end{array}$ & 2,6 & 2,4 & 3,6 & 3,4 & 4,1 & 3,9 & 4,6 & 4,2 & 4,2 & 4,0 \\
\hline $\begin{array}{l}\text { Nível elevado de } \\
\text { exigências do professor em } \\
\text { relação ao } \\
\text { rendimento/comportamento } \\
\text { do aluno }\end{array}$ & 2,4 & 2,3 & 3,2 & 3,0 & 3,6 & 3,5 & 4,4 & 4,2 & 4,2 & 4,1 \\
\hline $\begin{array}{l}\text { Avaliação não objetiva do } \\
\text { professor dos } \\
\text { conhecimentos dos alunos }\end{array}$ & 2,7 & 2,5 & 3,6 & 3,6 & 4,3 & 4,3 & 5,0 & 5,0 & 4,9 & 4,9 \\
\hline
\end{tabular}

Legenda: $\mathrm{m}$ - masculino; $\mathrm{f}$ - feminino.

As razões apresentadas na Tabela 2 podem ser relacionadas a três aspectos diferentes na realização da atividade escolar: qualificação profissional do professor (autoritarismo, baixo nível de profissionalismo), controle do rendimento dos estudantes nas atividades de estudo (nível elevado de cobrança em relação ao rendimento e ao comportamento do aluno, avaliação não-objetiva dos conhecimentos do aluno), contradições de cunho social e de status que surgem no decorrer do processo de atividades escolares (competição pela liderança, tendência para mostrar superioridade no grupo).
Como se vê, os dados apresentados na Tabela 2 permitem afirmar a respeito de dois tipos de situações de conflito que surgem no processo da atividade de estudo e circunscrevem a manifestação de agressão do aluno ao professor. Um deles está ligado ao papel de controle e avaliação do professor; o outro, à mudança das relações sociais e de papéis no âmbito das atividades escolares.

Vale notar que, ao interpretar os resultados apresentados, discutimos a situação do ponto de vista do aluno. Todavia, como os dados foram obtidos por meio de questionários aplicados a professores, temos fundamentos 
para falar sobre o surgimento de uma reflexão peculiar crítica dos professores a respeito de sua realização profissional. Não tememos indicar como momentos mais complexos a execução inadequada pelo professor da função de controle do rendimento dos alunos nos anos finais da escola (avaliação não objetiva dos alunos) e a realização inadequada da sua posição social e do seu papel na relação com o aluno, no âmbito da atividade escolar.

\section{Fatores sociais}

Um grupo especial de razões que circunscrevem o comportamento agressivo do adolescente em relação ao professor é formado por fatores que se caracterizam pelas peculiaridades da socialização fora dos muros da escola. Nesse grupo, encontram-se, por um lado, aspectos relacionados a situações familiares inadequadas (escândalos, alcoolismo dos responsáveis, ausência de controle, rigidez excessiva no trato com a criança, desrespeito dos responsáveis em relação ao professor de seus filhos); por outro, está a influência negativa de coetâneos (más companhias).

A média das notas atribuídas às razões que circunscrevem o comportamento agressivo do aluno dirigido ao professor é apresentada na Tabela 3. Esses dados mostram o crescimento gradativo do significado dos parâmetros do $2^{\circ}$ ao $9^{\circ}$ ano.
1- Segundo os professores, o sistema de relações sociais e de papéis professor-aluno é percebido pelos escolares dos anos iniciais como um regulamento rígido, sendo as manifestações de agressão do aluno ao professor vistas como um tabu. $\mathrm{O}$ único fator dominante que motiva a manifestação de agressão ao professor, nessa idade, é a ameaça de comunicar aos responsáveis o mau comportamento ou aproveitamento. Pode-se supor que o mecanismo de atualização da agressão infantil, nesse caso, será o 'medo de perder o amor dos responsáveis'. Isso, por sua vez, permite supor que o medo é um instrumento importante do professor para influenciar a criança.

2- Ao analisar as razões mais significantes da agressão infantil ao professor, no limiar entre o primeiro e o segundo segmento do EF, é importante destacar dois momentos: primeiramente, em comparação aos anos iniciais, eleva-se consideravelmente o significado das razões relacionadas às especificidades da socialização fora dos muros da escola: uma atmosfera ruim na família, muita rigidez no trato com a criança na família, desrespeito dos responsáveis em relação ao professor, más companhias; em segundo lugar, com o ingresso na adolescência,

Tabela 3 - Avaliação pelos professores dos fatores sociais que se apresentam como razões para agressão de meninos e meninas ao professor (notas)

\begin{tabular}{|c|c|c|c|c|c|c|c|c|c|c|}
\hline \multirow{2}{*}{$\begin{array}{l}\text { Razões das manifestações } \\
\text { de agressão do aluno ao } \\
\text { professor }\end{array}$} & \multicolumn{2}{|c|}{$\begin{array}{l}2^{\circ} \text { ano } \\
92 \text { pessoas }\end{array}$} & \multicolumn{2}{|c|}{$\begin{array}{l}5^{\circ} \text { ano } \\
107 \text { pessoas }\end{array}$} & \multicolumn{2}{|c|}{$\begin{array}{l}7^{\circ} \text { ano } \\
116 \text { pessoas }\end{array}$} & \multicolumn{2}{|c|}{$\begin{array}{l}9^{\circ} \text { ano } \\
109 \text { pessoas }\end{array}$} & \multicolumn{2}{|c|}{$\begin{array}{l}11^{\circ} \text { ano } \\
103 \text { pessoas }\end{array}$} \\
\hline & $\mathrm{m}$. & f. & $\mathrm{m}$. & f. & $\mathrm{m}$ & f. & $\mathrm{m}$ & f. & $\mathrm{m}$. & f. \\
\hline $\begin{array}{l}\text { Relação desrespeitosa } \\
\text { responsáveis com } \\
\text { professor }\end{array}$ & 3,3 & 3,2 & 4,0 & 4,0 & 4,4 & 4,3 & 4,8 & 4,8 & 4,5 & 4,4 \\
\hline $\begin{array}{l}\text { Atmosfera de } \\
\text { na família } \\
\text { alcosavenças } \\
\text { alcoolismo } \\
\text { responsáveis, ausência des } \\
\text { controle) }\end{array}$ & 3,5 & 3,2 & 4,1 & 3,8 & 4,5 & 4,1 & 4,8 & 4,5 & 4,5 & 4,2 \\
\hline $\begin{array}{l}\text { Muita rigidez da família no } \\
\text { trato com a criança }\end{array}$ & 3,7 & 3,3 & 4,3 & 3,9 & 4,5 & 4,2 & 4,7 & 4,4 & 4,4 & 4,1 \\
\hline $\begin{array}{l}\text { Convivência com más } \\
\text { companhias }\end{array}$ & 3,8 & 3,6 & 4,3 & 4,2 & 4,9 & 4,8 & 5,2 & 5,0 & 5,0 & 4,8 \\
\hline
\end{tabular}

Legenda: $\mathrm{m}$ - masculino; $\mathrm{f}-$ feminino.

Assim, na idade de crise, que ocorre na transição da adolescência para a juventude, o significado da influência negativa do meio no comportamento do aluno, entre os muros da escola e, principalmente, na relação do aluno com o professor, se atualiza. Deve-se prestar atenção especial ao fato de que, a partir do $7^{\circ}$ ano, a influência negativa dos coetâneos (más companhias) é, segundo os professores, o fator mais significativo em comparação com a situação negativa no âmbito familiar.

$$
* *
$$

Vamos destacar apenas os principais resultados que permitem caracterizar a dinâmica etária da alteração do significado das diversas razões para o comportamento agressivo de alunos dirigido ao professor. eleva-se o significado da dominante motivacional que era característica também dos anos iniciais. Entretanto, nessa fase, o contexto social da relação professor-aluno-responsáveis torna-se mais complexo. Ao ampliarmos o conjunto das razões significantes das relações criança-responsáveis (ameaças de comunicar aos pais o mau comportamento ou rendimento do aluno, humilhação dos responsáveis, fatores sociais negativos da educação), os professores, ao mesmo tempo, evidenciam a tentativa de se "intrometer" no sistema da relação criança-responsáveis. Em outras palavras, na relação com o adolescente, os professores apelam para o micromeio deste com o intuito de atingir seus objetivos pedagógicos, o que provoca uma reação agressiva. Quando o professor comunica ao responsável o mau comportamento ou rendimento 
da criança, está, na verdade, castigando-a com “as mãos” dos responsáveis e se desresponsabilizando. Quando o professor ofende a personalidade dos responsáveis pelo aluno, põe em dúvida a autoridade dos responsáveis pela criança, adentrando na relação íntima criança-responsáveis.

3- $\mathrm{Na}$ etapa de transição para a adolescência $\left(7^{\circ}\right.$ ano), eleva-se o significado dos fatores negativos do meio social como razões que explicariam o comportamento agressivo dos alunos em direção ao professor. Além disso, começam a surgir mais situações conflituosas relacionadas à atividade de estudo das quais decorre a agressão do aluno ao professor. O fator mais significativo, nesse caso, é a avaliação não objetiva dos conhecimentos do aluno feita pelo professor. Além disso, nessa idade, o grupo de razões torna-se mais complexo e relaciona-se às ações do professor que provocam o comportamento agressivo nos alunos. Assim, a avaliação dos próprios professores a respeito de humilhações feitas aos alunos como razão principal para a agressividade infantil evidencia a transição do sistema de relações sociais e de papéis professor-aluno da esfera institucional para a esfera interpessoal de relações, diminuindo, com isso, a distância social entre os sujeitos do processo pedagógico.

4- São bem interessantes as mudanças que ocorrem na etapa final do segundo segmento do EF ( $9^{\circ}$ ano). Nesse limiar etário, o fator menos significativo, segundo os professores, é a ameaça de comunicar aos responsáveis o mau comportamento e aproveitamento do aluno. Ao mesmo tempo, eleva-se o significado das razões ligadas às características negativas do meio social para manifestação de agressão ao professor. Além disso, o aluno dos anos finais mostra-se mais sensível às ações humilhantes do professor, as quais provocam reação de defesa. Chama a atenção o amplo conjunto de razões para a agressividade infantil assinaladas pelos próprios professores: antipatia do professor em relação ao aluno, humilhação, atribuição de rótulos ao aluno (estigmas), emprego de força física contra o aluno. É importante destacar também que, para esse grupo etário, é característica a ação de mecanismos de autoidentificação do adolescente com grupos ao manifestar agressão ao professor. Por exemplo, quando a relação do professor com os responsáveis pelo aluno é negativa, o comportamento agressivo do escolar liga-se à identificação da criança com seus responsáveis e possui um aspecto de defesa. A avaliação dos professores acerca das razões que refletem o nível das relações sociais dos alunos com seus coetâneos (relação desrespeitosa do professor com toda a turma, resolução injusta ou inadequada de conflito) pressupõe a autoidentificação com um grupo. Acrescentamos apenas que, nessa idade, o aluno torna-se muito sensível a muitas manifestações negativas voltadas para ele, pois até mesmo um fato insignificante pode provocar uma reação agressiva. A confirmação disso é a avaliação dos professores das características individuais como razões significantes para a agressividade na adolescência (instabilidade emocional, falta de educação/grosseria).

5- A análise dos dados obtidos mostra que, na etapa final da escola ( $11^{\circ}$ ano), as novas dominantes motivacionais, que caracterizam a agressão ao professor na adolescência, não são assinaladas pelos professores. A nosso ver, isso evidencia certa estabilidade nas relações professor-aluno, o que leva à ausência de novos motivos que circunscrevem o caráter social de papéis e interpessoal da relação de convivência.

\section{Informações sobre os autores:}

\section{Vladimir Sobkin}

\section{(iD) https://orcid.org/0000-0002-2339-9080}

ittp://www.psy.msu.ru/people/sobkin.html

Formou-se na Universidade Lomonosov de Moscou em 1972, é doutor em psicologia e professor do Centro de Formação em Sociologia, da Instituição Federal Estatal Científica de Educação da Federação Russa. É autor de mais de 14 trabalhos acadêmicos e mais de 350 publicações com temas do campo da sociologia da educação, da psicologia infantil e etária, da psicologia de comunicação e psicologia da arte. É autor de uma série de trabalhos acadêmicos editados e publicados fora da Rússia (EUA, França, Austrália, Polônia, entre outros).

\section{Anna Fomitchenko}

\section{iD https://orcid.org/0000-0001-8236-610X}

吾 http://www.osu.ru/doc/1041/kaf/6402/prep/51939

Em 2004, graduou-se pela Universidade Estatal de Orenburg (Rússia). Em 2014, defendeu a tese de doutorado na linha de pesquisa Psicologia pedagógica, tendo como tema A percepção e a compreensão pelos professores do comportamento agressivo dos alunos. Em 2016, recebeu o Prémio do Governador da Região de Orenburg por suas contribuições para a ciência. É autora de 33 publicações. Desenvolve pesquisas no campo da psicologia das idades e da psicologia pedagógica.

\section{Contribuição dos autores:}

Ambos os autores colaboraram ao longo do processo, desde a elaboração até a revisão final do manuscrito. Os autores aprovaram o manuscrito final para publicação.

\section{Como citar este artigo:}

\section{ABNT}

SOBKIN, Vladimir; FOMITCHENKO, Anna. Compreensão de professores acerca dos motivos da agressão de estudantes. Fractal: Revista de Psicologia, Niterói, v. 32, n. esp., p. 190-198, jun. 2020. https://doi.org/10.22409/1984-0292/v32_i-esp/38851

\section{APA}

Sobkin, V., \& Fomitchenko, A. (2020, Junho). Compreensão de professores acerca dos motivos da agressão de estudantes. Fractal: Revista de Psicologia, 32(esp.), 190-198. doi: https://doi. org/10.22409/1984-0292/v32_i-esp/38851 


\section{Copyright:}

Copyright (C 2020 Sobkin, V., \& Fomitchenko, A. Este é um artigo em acesso aberto distribuído nos termos da Licença Creative Commons Atribuição que permite o uso irrestrito, a distribuição e reprodução em qualquer meio desde que o artigo original seja devidamente citado.

Copyright (C 2020 Sobkin, V., \& Fomitchenko, A. This is an Open Access article distributed under the terms of the Creative Commons Attribution License, which permits unrestricted use, distribution, and reproduction in any medium, provided the original article is properly cited.

\section{Referências}

BANDURA, Albert; UOLTERS, Richard. Podrostkovais agressia: izutchenie vilania vospitania i semeinirh otnocheni. [Agressão na adolescência: estudo sobre a influência da educação e das relações familiares]. Moskva: Aprel Press, EKSMO-Press, 2000.

BERON, Robert; RITCHARDSON, Debora. Agressia. [Agressão]. Sankt-Petersburg: Piter, 2001.

BIUTNER, Cristian. Jit s agressivnimi detmi. [Viver com crianças agressivas]. Moskva: Pedagoguika, 1991.

BOJOVITCH, Lidia Ilinitchna. Litchnost $i$ ieio formirovanie $v$ detskom vozraste. [Personalidade e sua formação na infância]. Moskva: Prosveschenie, 1968.

BRESLAV, Grigori Emanuilovitch. Psirrologuitcheskaia korrektsia detskoi e podrostkovoi agressivnosti: utchebnoie possobie dlia spetsialistov i diletantov. [Correção psicológica da agressividade infantil e na adolescência: livro didático para especialistas e diletantes]. Sankt-Petersburg: Retch, 2007.

DRAGUNOVA, Tatiana Vladimirovna. Problema konflikta $\mathrm{v}$ podrostkovom vozraste. [O problema do conflito na adolescência]. Voprosi psirrologuii, n. 2, p. 25-39, 1972.

ELKONIN, Daniil Borissovitch. Detskaia psirrologuia. [Psicologia infantil]. Moskva: Utchpedgiz, 1960.

ENIKOLOPOV, Serguei Nikolaievitch. Nekotorie problemi psirrologuii agressivnogo povedenia detei i podrostkov. [Alguns problemas da psicologia do comportamento agressivo de crianças e adolescentes]. Sotsialnaia $i$ klinitcheskaia psirriatria, n. 2, p. 40-45, 2002.

ERIKSON, Eric. Identitchnost: iunost i krizis. [Identificação e crise]. Moskva: Flinta, MPSI e Progress, 2006.

ЭСКАЛАЦИЯ насилия в школах: за 2 года количество нападений на учителей выросло в полтора раза. [Escalada da violência nas escolas: em dois anos, a quantidade de ataques a professores cresceu muito]. 18 maio 2007. Disponível em: http://www.newsru.com/russia/18may2007/school.html. Acesso em: 19 dez. 2018.

GRATCHIOVA, Alla Mirrailovna et al. Psirosemantitcheski analiz ponimania motivatsionnoi strikturi povedenia kinopersonaja. [Análise psicosemântica da compreensão da estrutura do comportamento de personagem de filme]. Voprosi psirrologuii, n. 5, p. 123-131, 1988.

GUTKINA, Nina Iossivna. Psirrologuitcheskie problemi obschenia utchitelia s podrostkami. [Problemas psicológicos da relação de convivência do professor com adolescentes]. Voprosi psirrologuii, n. 2, p. 99-106, 1984.
KOLOSSOVA, Svetlana. Agressia i agressivnost. [Agressão e agressividade]. Chkolni psirrolog, n. 25-26, p. 4-7; n. 27, p. 1620; n. 28, p. 1-2, 2000.

KREIRHI, Barbara. Sotsialnaia psirrologuia agressii. [Psicologia social da agressão]. Sankt-Petersburg: Piter, 2003.

MAKARENKO, Anton Semionovitch. Pedagoguitcheskaia poema. [Poema pedagógico]. Moskva: Pedagoguika, 1981.

REAN, Artur Aleksandrovitch A. Psirrologuia litchnosti: Sotsiologuia, povedenie, obschenie. [Psicologia da personalidade: Sociologia, comportamento, relação de convivência]. Moskva: Ast, 2007.

SOBKIN, Vladimir. Problemi tolerantnosti $v$ podrostkovoi subkulture: trudi po sotsiologuii obrazovania. [Problemas de tolerância na subcultura adolescente: estudos de sociologia da educação]. Moskva: Tsentr sotsiologuii obrazovania, RAO, 2003. T. VIII, Vip. XIII.

SOBKIN, Vladimir et al. Podrostok: normi, riski, deviatsii. [Adolescente: normas, riscos e desvios]. In: _. Trudi po sotsiologuii obrazovania. Moskva: Tsentr sotsiologuii obrazovania RAO, 2005. T. X, Vip. XVII.

SOBKIN, Vladimir; FOMITCHENKO, Anna. O situatsiarh agressivnogo povedenia mejdu utchenikami (po materialam kontet-analiza utchitelskirh sotchineni). [Sobre situações de comportamento agressivo entre alunos (com base em materiais da análise das redações de professores]. In:

Sotsiologuia obrazovania. Trudi po sotsiologuii obrazovania. Moskva: Institut sotsiologuii obrazovania RAO, 2011. T. XV, Vip. XXVI, p. 177-204.

SOBKIN, Vladimir; MARKINA, Olga. Motivatsionnaia struktura povedenia personaja (po materialam vospriatia filma Rolana Bikova "Tchutchelo". [Estrutura motivacional do comportamento do personagem (com base em materiais de percepção do filme de Rolan Bikov "Espantalho"]. Eksperimentalnaia psirrologuia, n. 1, p. 61-83, 2009.

SOBKIN, Vladimir; MARKINA, Olga. Film "Tchutchelo" glazami sovremenirh chkolnikov. [O filme "Espantalho" pelos olhos de escolares da contemporaneidade]. In: Trudi po sotsiologuii obrazovania. Moskva: Institut sotsiologuii obrazovania RAO, 2010. T. XIV, Vip. XVV.

SOBKIN, Vladimir; PISSARSKI, Piotr Savvitch; KOLOMIETS, Iuri. Utchitelstvo kak sotsialno-professionalnaia grupa. [A docência com um grupo sócio-profissional]. Moskva: Rossiskaia academia obrazovania, TsSO RAO, 1996.

SURHOMLINSKI, Vassili Aleksandrovitch. Metodika vospitania kollektiva. [Metodologia de educação do coletivo]. Moskva: Prosveschenie, 1981. 